\title{
Avaliação das Representações Gráficas das Cartas Topográficas Brasileiras para Pessoas com Deficiência na Percepção de Cores
}

\section{Evaluation of Graphic Representations of Brazilian Topographic Maps for People with Disabilities in Color Perception}

Hélder do Carmo Dias ${ }^{1}$, Jackson Viana Amarante ${ }^{2}$, Afonso de Paula dos Santos ${ }^{3}$, Marconi Martins Cunha ${ }^{4}$ e Lígia da Silva Barbosa ${ }^{5}$

1 Universidade Federal de Viçosa, Departamento de Engenharia Civil, Viçosa, Brasil. helder.dias@ufv.br. ORCID: https://orcid.org/0000-0003-0576-4176

2 Universidade Federal de Viçosa, Departamento de Engenharia Civil, Viçosa, Brasil. jackson.amarante@ufv.br. ORCID: https://orcid.org/0000-0002-2088-8460

3 Universidade Federal de Viçosa, Departamento de Engenharia Civil, Viçosa, Brasil. afonso.santos@ufv.br. ORCID: https://orcid.org/0000-0001-7248-4524

4 Universidade Federal de Viçosa, Departamento de Engenharia Civil, Viçosa, Brasil. marconi.cunha@ufv.br. ORCID: https://orcid.org/0000-0003-0797-8530

5 Universidade Federal de Viçosa, Departamento de Engenharia Civil, Viçosa, Brasil. ligia.barbosa@ufv.br. ORCID: https://orcid.org/0000-0003-1929-8110

Resumo: O daltonismo afeta um a cada doze homens e uma a cada duzentas mulheres no mundo. Como a cor é uma variável visual largamente utilizada na transmissão de informações nos mapas, é importante que o cartógrafo leve em consideração as limitações deste público, a fim de evitar ruídos na comunicação. A Lei n ${ }^{\circ} 10.098$, de 19 de dezembro de 2000 destaca a obrigatoriedade por parte do poder público em eliminar estas barreiras e buscar sempre a acessibilidade. Sendo assim, este trabalho teve como finalidade analisar a adequabilidade das cartas topográficas produzidas com simbologia conforme os padrões da Infraestrutura Nacional de Dados Espaciais (INDE) para usuários com deficiência na percepção de cores. A avaliação foi realizada em cartas topográficas nas escalas de 1:25.000 e 1:50.000, primeiramente com uso de simuladores de visão de cores e, posteriormente, por meio de questionário aplicado a indivíduos que possuem ou não está limitação. Os indivíduos foram classificados em grupos conforme a presença ou ausência da condição e de seu grau de familiaridade com os produtos cartográficos avaliados. As análises foram realizadas de forma comparativa entre os grupos de familiaridade equivalente e mostraram fortes indícios de que a deficiência na percepção de cores afetou negativamente a experiência dos usuários na leitura e interpretação dos produtos desenvolvidos a partir das normatizações da INDE.

Palavras-chave: Cartografia. Daltonismo. Acessibilidade. INDE.

\begin{abstract}
Color blindness affects one in every twelve men and one in every two hundred women in the world. As color is a visual variable widely used in the transmission of information on maps, it is important that the cartographer takes into account the limitations of this audience, in order to avoid noise in communication. Law No. 10,098, of December 19, 2000, highlights the obligation on the part of the government to eliminate these barriers and always seek accessibility. Therefore, this work aimed to analyze the suitability of topographic maps produced with symbology according to the standards of the National Spatial Data Infrastructure (INDE) for users with disabilities in color perception. The assessment was carried out on topographic maps in the scale of 1:25,000 and 1: 50,000, first with the use of color vision simulators and, later, through a questionnaire applied to individuals who have or do not have this limitation. The individuals were classified into groups according to the presence or absence of the condition and their degree of familiarity with the evaluated cartographic products. The analyzes were carried out comparatively between groups of equivalent familiarity and showed strong evidence that the deficiency in color perception negatively affected the users experience in reading and interpreting the products developed from the INDE standards.
\end{abstract}

Keywords: Cartography. Color blindness. Accessibility. INDE. 


\section{INTRODUÇÃO}

Dentro das esferas política e administrativa, os mapas desempenham importante função na tomada de decisões, no planejamento, na execução e acompanhamento de diversos tipos de projetos. Nesse contexto, reconhecendo a importância desses dados para tais finalidades, o Brasil aprovou em 27 de novembro de 2008 o Decreto $\mathrm{N}^{\mathrm{o}}$ 6.666, que instituiu a Infraestrutura Nacional de Dados Espaciais (INDE). A INDE consiste em um conjunto integrado de tecnologias; políticas; mecanismos e procedimentos de coordenação e monitoramento; padrões e acordos, necessário para facilitar e ordenar a geração, o armazenamento, o acesso, o compartilhamento, a disseminação e o uso dos dados geoespaciais de origem federal, estadual, distrital e municipal (BRASIL, 2008; SILVA, SANTOS, LISBOA FILHO, 2020).

Para atingir os seus objetivos, a INDE dispõe de várias especificações técnicas. Dentre estas, pode-se citar a Especificação Técnica de Produtos de Conjuntos de Dados Geoespaciais (ET-PCDG), que tem a função de definir os padrões a serem observados na elaboração de produtos de conjuntos de dados geoespaciais. Em seu escopo, esta norma estabelece folhas modelo de produtos do tipo carta com seus respectivos padrões para as variáveis visuais e simbologias a serem adotadas.

Dentre as oito variáveis visuais (dimensões x e y do plano, tamanho, valor, granulação, cor, orientação e forma) definidas por Bertin (1967) e Martinelli (2007), a cor é um elemento de destaque devido ao seu grande poder na comunicação visual e sua atuação na emotividade humana. Esta variável tem o papel de auxiliar o usuário a decifrar os símbolos e realizar inferências a partir deles (PETERSON, 2008). Ainda segundo esta autora, se o utilizador do mapa não consegue interpretar corretamente o produto, significa que houve uma falha de comunicação por parte do produtor. Estas falhas de comunicação são mais prováveis de ocorrer quando o produtor e o utilizador percebem a cor de formas diferentes. Logo, é importante que o cartógrafo entenda as particularidades dos indivíduos com deficiência na percepção de cores, a fim de utilizar uma comunicação visual eficiente e acessível a todos os indivíduos.

Segundo Kim, Kim e Yang (2007), as deficiências na visão de cores são um grupo de condições que afetam a percepção de cores dos indivíduos. O daltonismo é uma dessas condições que afeta cerca de $8 \%$ da população masculina e $0,5 \%$ da população feminina (MOLLON, POKORNY, KNOBLAUCH, 2003; BRUNI, CRUZ, 2006). Considerando-se as projeções populacionais para o ano de 2021, realizadas por IBGE (2021), cerca de 8,8 milhões de brasileiros seriam portadores de algum tipo de daltonismo. Desta forma, nota-se que são grandes as chances de haver um considerável número de usuários dos produtos da INDE com deficiência na visão de cores.

Peterson (2008) destaca ainda a importância de se levar em conta a acessibilidade dos indivíduos com deficiência na percepção de cores no design de produtos cartográficos, uma vez que negligenciá-los pode resultar em falhas severas na comunicação.

No Brasil, a acessibilidade é garantida por lei. O artigo 17 da Lei ${ }^{\circ} 10.098$, de 19 de dezembro de 2000 afirma que:

O Poder Público promoverá a eliminação de barreiras na comunicação e estabelecerá mecanismos e alternativas técnicas que tornem acessíveis os sistemas de comunicação e sinalização às pessoas portadoras de deficiência sensorial e com dificuldade de comunicação, para garantir-lhes o direito de acesso à informação, à comunicação, ao trabalho, à educação, ao transporte, à cultura, ao esporte e ao lazer (BRASIL, 2000, Art. 17).

Sendo assim, observada a relevância de se promover a inclusão, para possibilitar o acesso e promover uma comunicação sem barreiras aos brasileiros com deficiência na percepção de cores, é necessário avaliar os padrões de cores das simbologias utilizadas nos produtos expostos na ET-PCDG, que é a norma que até o presente momento define os padrões para as variáveis visuais e simbologias. Sendo assim, o objetivo desta pesquisa é analisar a adequabilidade das cartas topográficas produzidos com simbologia conforme padrões da INDE para usuários com deficiência na percepção de cores. Vale ressaltar que a norma ET-RDG ainda não foi publicada.

Para avaliar a acessibilidade da comunicação visual dos produtos cartográficos que seguem os padrões da ET-PCDG, foram aplicados questionários às pessoas com deficiências na percepção de cores; tomando por base as metodologias utilizadas Oliveira (2015) e Maia (2013). 
Além disso, como nos trabalhos de Oliveira (2015) e Kröger, Schiewe, e Weninger, (2013), foram utilizados ainda simuladores que auxiliam o produtor com visão normal de cores (sem a presença do daltonismo) a entender melhor as particularidades deste grupo de usuários. Estes algoritmos emulam deficiências na visão de cores e auxiliam os cartógrafos na geração de mapas acessíveis (PETERSON, 2008).

\section{DEFICIÊNCIA EM PERCEPÇÃO DE CORES}

A deficiência na visão de cores é definida como a dificuldade em distinguir uma cor da outra, é uma disfunção que altera a sensibilidade das células fotorreceptoras presentes nos cones, localizados na retina dos olhos, o que faz prejudicar a visualização de todo o espectro luminoso (MAIA, SPINILLO, 2013). Essa deficiência visual pode ser tanto de forma genética como de forma adquirida (SARDEGNA et al., 2002). Quando essa deficiência é congênita, ela é popularmente conhecida como daltonismo (BRUNI, CRUZ, 2006).

O daltonismo afeta predominantemente os homens, acometendo 1 a cada 12 homens e 1 a cada 200 mulheres (BIRCH, 2012). O gene causador desta doença está relacionado ao cromossomo X. Como os homens possuem um único cromossomo $\mathrm{X}(\mathrm{XY})$ basta apenas que este cromossomo apresente o gene característico desta doença para o homem ser portador da mesma. No entanto, como as mulheres possuem dois cromossomos $\mathrm{X}(\mathrm{XX})$, é necessário que ambos contenham essa disfunção genética para que a mulher seja portadora. Nestes casos não há cura ou tratamento, sendo os dois olhos afetados (NEIVA, 2008).

Já a deficiência na visão de cores de forma adquirida pode ser oriunda do envelhecimento ou de forma secundária. Com o avanço da idade o indivíduo pode desenvolver doenças como retinopatia diabética, catarata ou glaucoma. Já em sua forma secundária, pode ser proveniente de lesões no córtex cerebral, nervo ótico ou retina. Nestes casos, o olho doente é na maioria das vezes o olho afetado, e apresenta uma significativa melhora na percepção de cores ao se realizar um tratamento adequado (SARDEGNA et al., 2002).

Uma teoria que auxilia a compreensão da percepção de cor nos seres humanos é a tricromática. Essa teoria estabelece que nossa retina é composta de células fotorreceptoras, denominadas cones, que se sensibilizam com luzes nas cores vermelha, verde e azul (SILVEIRA, BARTHEM, 2016). Para a compreensão das demais cores e tons, se faz necessária uma estimulação relativa dos três cones. (DENT, TORGUSON, HODLER, 2009).

Os cones que identificam a cor azul são sensíveis aos comprimentos de onda por volta de 440 nanômetros. Já os cones que reconhecem a cor verde são sensíveis aos comprimentos de onda de, aproximadamente, 540 nanômetros. Por fim, os cones que detectam a cor vermelha são sensíveis aos comprimentos de onda próximos de 570 nanômetros (MACEACHREN, 1995), conforme a Figura 1.

Figura 1 - O espectro de absorção dos receptores para vermelho, verde e azul dos cones.

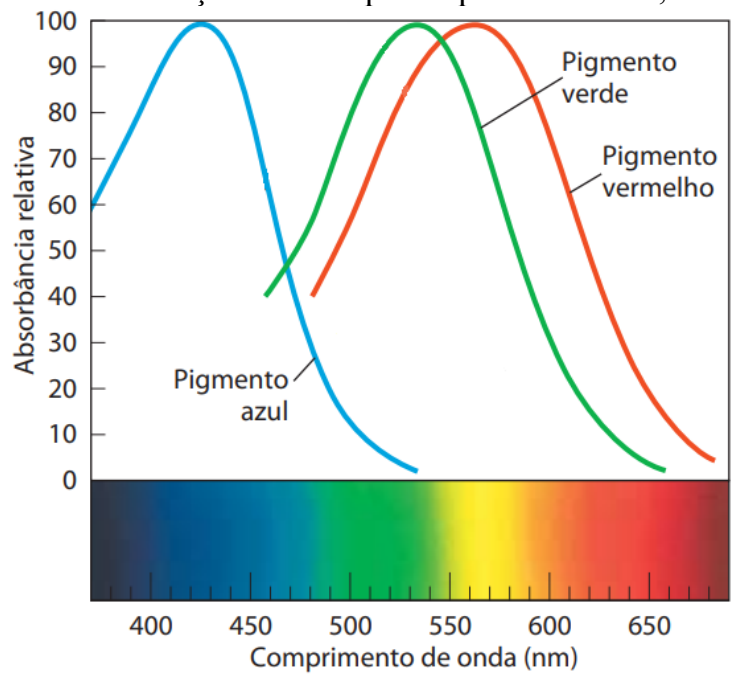

Fonte: Adaptado de Nelson e Cox (2014, p. 480).

Há três classificações para essa percepção de cores: tricromatas, dicromatas e monocromatas (SARDEGNA et al., 2002). Pessoas com o funcionamento normal dos três cones possuem a visão normal e são classificadas como tricromatas normais (identificam todas as cores). Já pessoas com algum tipo de 
deficiência na visão de cores (daltônicos) podem ser classificadas como: monocromatas, dicromatas ou tricromatas anômalos (POKORNY et al., 1979).

Tricromatas anômalos se refere a indivíduos com o funcionamento dos três cones, entretanto, comprimentos de ondas diferentes são absorvidos por um desses cones, evidenciando um deslocamento de sensibilidade da retina (BEAR, 2002). Considerando o funcionamento regular de dois cones, o indivíduo é classificado como dicromata. Nesta situação, o indivíduo identifica um número menor de cores comparado aos tricromatas anômalos, uma vez que este só identifica duas cores primárias. Por fim, o indivíduo que possui o funcionamento correto de apenas um cone é classificado como monocromata, e não possui a capacidade de distinguir qualquer cor, enxergando apenas escala de cinza (GOLDSTEIN, 2009).

No que se refere à deficiência na identificação de algumas cores, os tricromatas anômalos são classificados em: tritanômalos (com deficiência no azul), deuteranômalos (com deficiência no verde) e protanômalos (com deficiência no vermelho). Já os dicromatas são classificados em: tritanopes (com deficiência no azul), deuteranopes (com deficiência no verde) e protanopes (com deficiência no vermelho) (FAIRCHILD, 2013).

\section{TESTE DE ISHIHARA}

Com relação à identificação do daltonismo, existem vários testes clínicos para a avaliação da percepção de cores, sendo o mais utilizado mundialmente o teste de Ishihara, devido a sua fácil aplicação e eficiência na detecção desta deficiência (CUNHA, 2019). Este teste foi desenvolvido para a detecção e diagnóstico da percepção de cores em indivíduos com alteração congênita, sendo publicado pela primeira vez em Tóquio em 1917.

Esse teste consiste na apresentação de placas com números e linhas a serem identificados, estando atualmente disponíveis nas versões de 24 e 38 placas (DAIN, 2004). Estas placas são constituídas por diversos círculos agrupados com diâmetros entre 1 e 5 milímetros, representados por cores caracterizadas pela luminosidade, tonalidade e saturação (URBANO, 1978). Pessoas não daltônicas são capazes de identificar todos os números e linhas presentes nas placas, já indivíduos com deficiência na percepção de cores não são capazes de identificar todos os números e linhas que se encontram nestas placas.

Segundo Dantas (1996), apesar das limitações, o teste de Ishihara é a tábua pseudoisocromática mais usada na identificação das discromatopsias congênitas. Já Dain (2004), destaca o pioneirismo comercial do teste e afirma que vários estudos de eficiência do teste mostraram que o teste de Ishihara continua sendo o exame considerado como "padrão ouro" para a detecção rápida de deficiências congênitas para visão de cores.

\section{DALTONISMO E CARTOGRAFIA}

Neste item serão apresentados alguns estudos que relacionam daltonismo e cartografia.

O trabalho de Jenny e Kelso (2007) aborda a utilização do software Color Oracle para o auxílio da construção de mapas tanto para daltônicos (deuteranopes, protanopes ou tritanopes) quanto para não daltônicos. Este programa filtra mapas e gráficos digitais em tempo real, permitindo ao cartógrafo ter a percepção de como os daltônicos visualizam um mapa e ter a noção se as cores utilizadas são legíveis para todos. A Figura 2 demonstra a utilização deste software. 
Figura 2 - Demonstração da visualização de um mapa por um daltônico deuteranope através do Color Oracle.
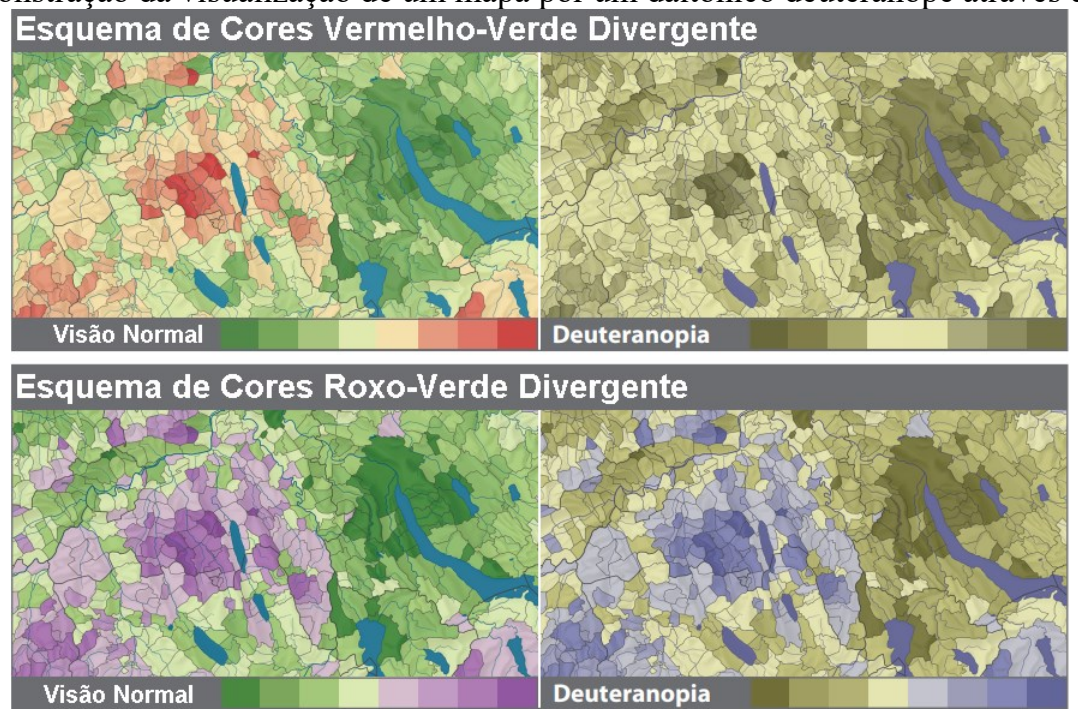

Fonte: Adaptado de Jenny e Kelso (2007, p. 64).

A utilização deste software como auxiliar na construção de mapas aliado à utilização das demais variáveis visuais permite ao cartógrafo construir e transmitir informações cartográficas acessíveis a todos os potenciais usuários.

Outro estudo que aborda o daltonismo na cartografia foi desenvolvido por Maia (2013). Neste trabalho foram avaliados os mapas da Rede Integral de Transporte de Curitiba, que é conhecida por ser exemplo de acessibilidade no âmbito de transporte público. Para isso, foram realizadas análises gráficas dos mapas disponíveis para os usuários e entrevistas com pessoas daltônicas e não daltônicas com o intuito de entender as diferenças na percepção das representações gráficas e cromáticas dos mapas.

O resultado da análise gráfica demonstrou que são vários os aspectos visuais que devem ser alterados visando atender aos daltônicos, sendo um desses a redução da combinação entre vermelho e verde para identificar os serviços do sistema de transporte, uma vez que a maioria dos daltônicos tem dificuldade na percepção dessas duas cores. Já no resultado das entrevistas foi possível identificar que os daltônicos apresentam maior dificuldade de compreensão dos mapas comparados aos não daltônicos, pelo fato do excesso de informações nos impressos e à representação cromática.

Ainda nesta linha, Oliveira et al. (2015) analisaram as representações cartográficas do Sistemas de Navegação e Guias de Rota em automóveis (SINGRA) baseados na percepção de cores de daltônicos dicromatas.

Neste trabalho foram utilizados dois sistemas de navegação em automóvel: o GARMIN nuvi 3460 (comercial) e o Google Maps Navigation (gratuito). A área de estudo adotada foi uma rotatória na cidade de Presidente Prudente (São Paulo) que continha diferentes números de faixas, além de diferentes classes de vias (rodovia, marginal, via urbana arterial e local, etc.). O levantamento dos dados foi realizado mediante a captura de tela simultânea em dois celulares que usavam os sistemas de navegação escolhidos enquanto o carro percorria a área de estudo. A simulação da visão de cores dos daltônicos dicromatas foi realizada por meio do software Color Oracle nas capturas de telas dos celulares que continham os softwares GARMIN nuvi $3460 \mathrm{e}$ Google Maps Navigation.

Os resultados obtidos a partir da simulação de visão de cores nos mapas exibidos pelo GARMIN nuvi 3460 e pelo Google Maps Navigation são apresentados nas Figuras 3 e 4. 
Figura 3 - Mapas do sistema GARMIN nuvi 3460 com a simulação da visão de cores do tricromata normal (a), para as visões de cores dos dicormatas protanope (b), deuteranope (c), e tritanope (d), utilizando o Color Oracle.

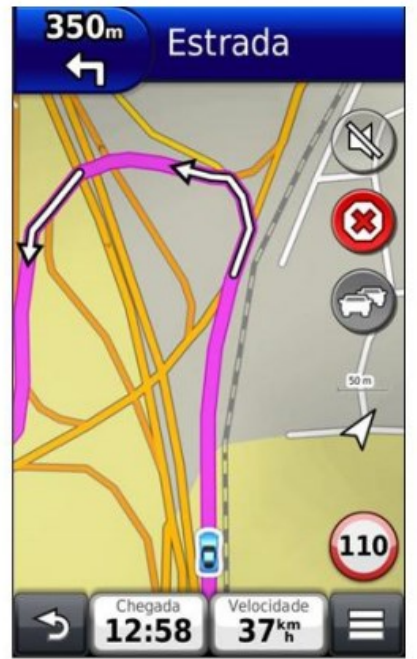

(a)

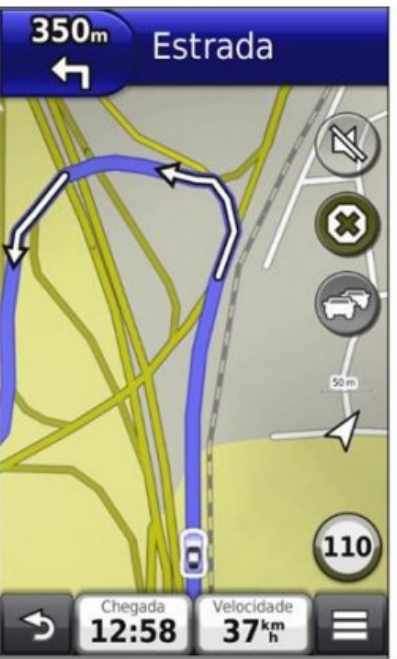

(b)

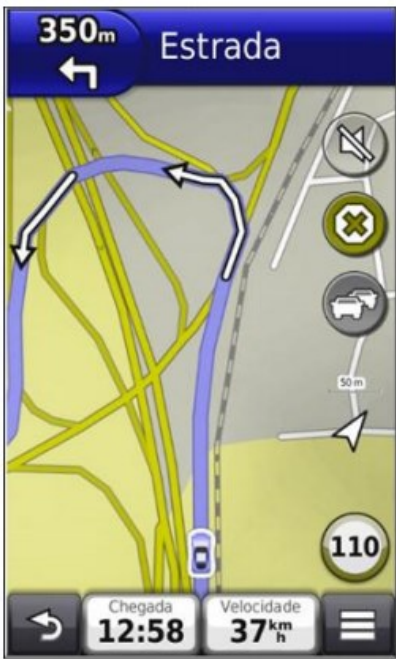

(c)

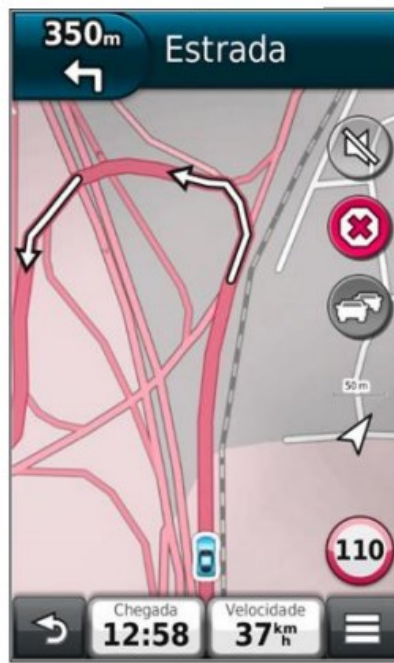

(d)

Fonte: Oliveira et al. (2015, p. 6261).

Figura 4 - Mapas do sistema Google Maps Navigation com a simulação da visão de cores do tricromata normal (a), para as visões de cores dos dicromatas protanope (b), deuteranope (c), e tritanope (d), utilizando o Color Oracle.

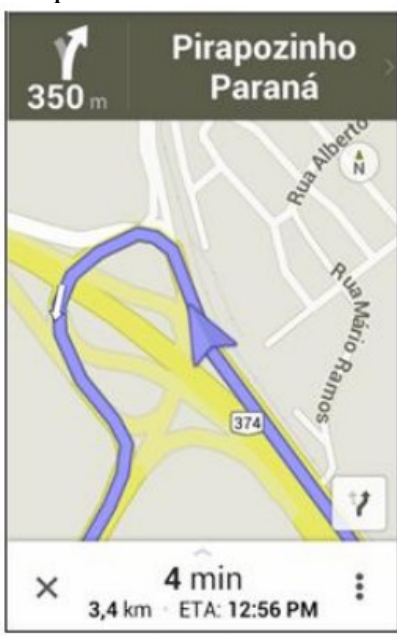

(a)

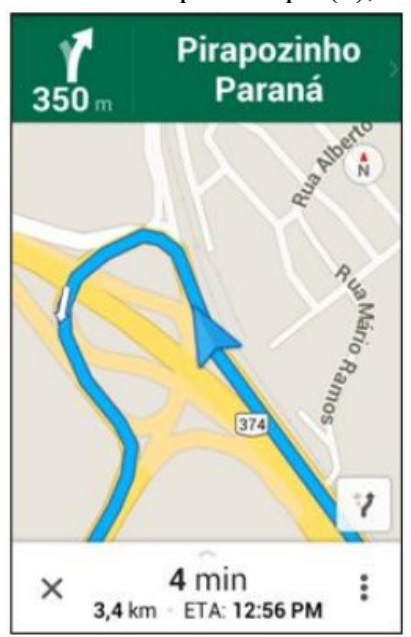

(b)

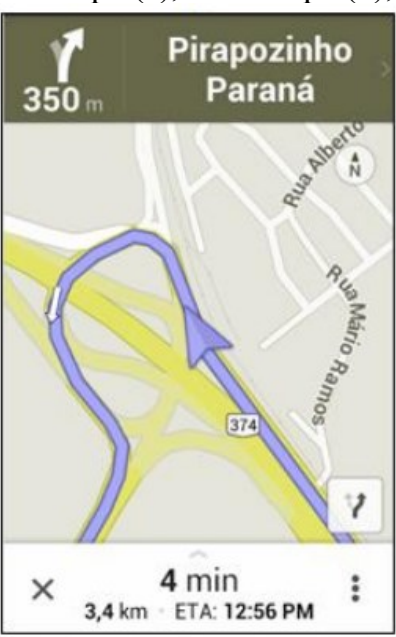

(c)

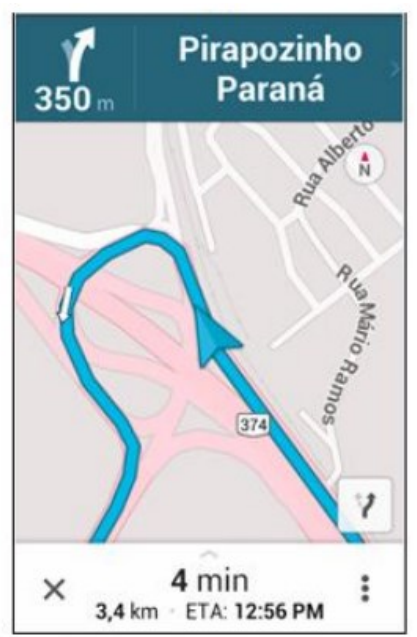

(d)

Fonte: Oliveira et al. (2015, p. 6262).

A partir dos resultados, os autores concluíram que houve uma perda de hierarquia visual entre as feições do mapa, considerando a percepção de cores dos dicromatas. Mas, destacaram que essa perda é maior nos mapas utilizados pelo GARMIN nuvi 3460, comparados ao mapa do Google Maps Navigation, o que implica na falta de distinção figura-fundo, resultando em problemas de legibilidade no mapa, o que acabou dificultando a compreensão das informações de navegação.

\section{METODOLOGIA}

Inicialmente foi feita a escolha de trechos em cartas produzidas de acordo com os padrões da INDE a serem analisados através do software Color Oracle de forma fosse possível delimitar amostras dos produtos que poderiam conter barreiras à leitura e interpretação das cartas às pessoas com deficiência na percepção de cores. Dentre os critérios observados nesta etapa estão: o contraste entre os elementos; legibilidade dos textos; alterações na percepção de hierarquia entre feições; e dificuldades de associação unívoca entre legenda e objetos.

Baseados nestes critérios foram selecionados os trechos I e II referente à carta SF-23-Z-B-IV-4-SO (escala 1:25.000) e o trecho III, da carta SB-21-V-B-II-2 (escala 1:50.000). Tais cartas são disponibilizadas no 
Banco de Dados Geográficos do Exército (BDGEX) e construídas seguindo as diretrizes da INDE. O trecho I foi escolhido pelo potencial identificado em gerar confusão entre curvas de nível mestras e rodovias entre todos os indivíduos envolvidos na pesquisa. Além disso, as análises com o simulador de cores indicaram possíveis alterações na hierarquia dos elementos nos trechos I e II. Eventuais dificuldades de leitura e identificação de cursos d'água também foram constatadas. As Figuras 5, 6, 7 e 8 mostram as simulações geradas pelo software Color Oracle para diferentes tipos de deficiência na visão de cores.

Figura 5 - Trechos dos produtos utilizados demonstrando a visão normal das cores.

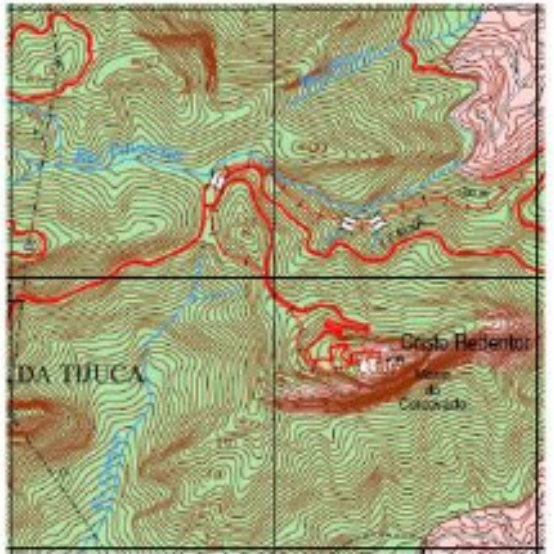

TRECHO I

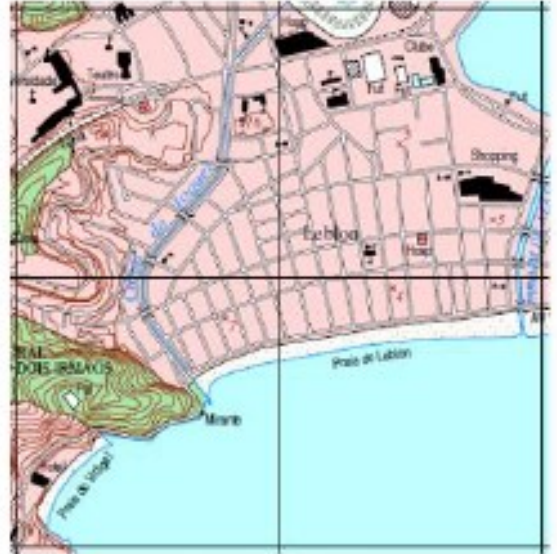

TRECHO II

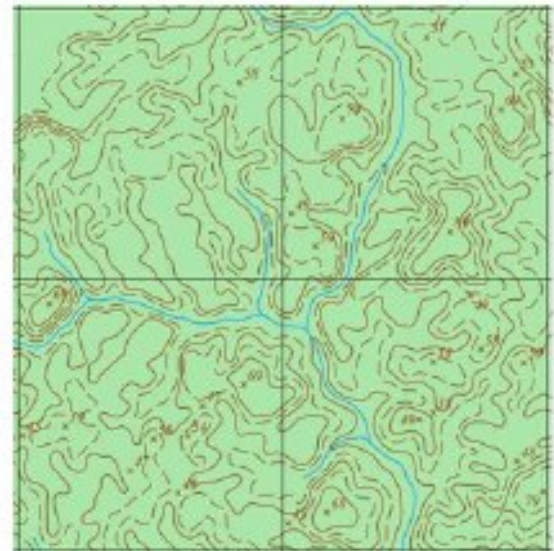

TRECHO III

Fonte: Adaptado de BDGEX (2021).

Figura 6 - Trechos dos produtos utilizados e as simulações geradas pelo Color Oracle para a deficiência Deuteranopia.

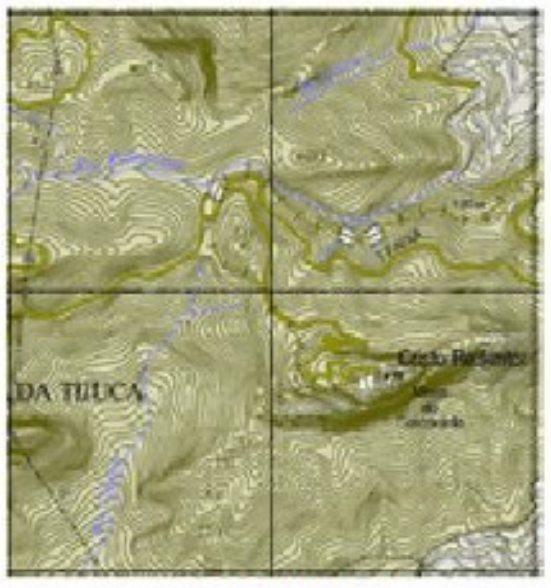

TRECHO I

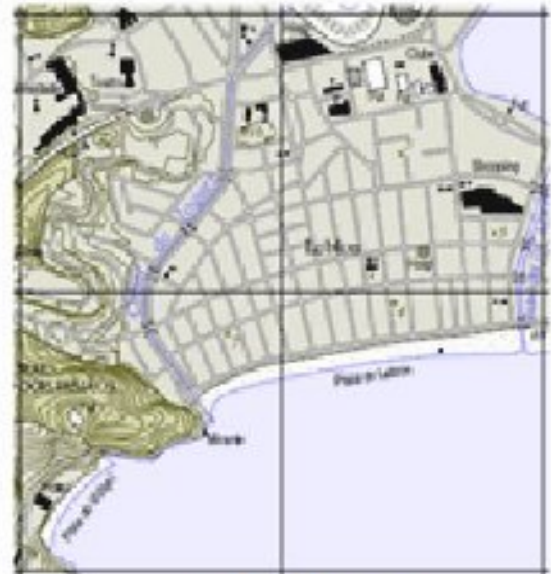

TRECHO II

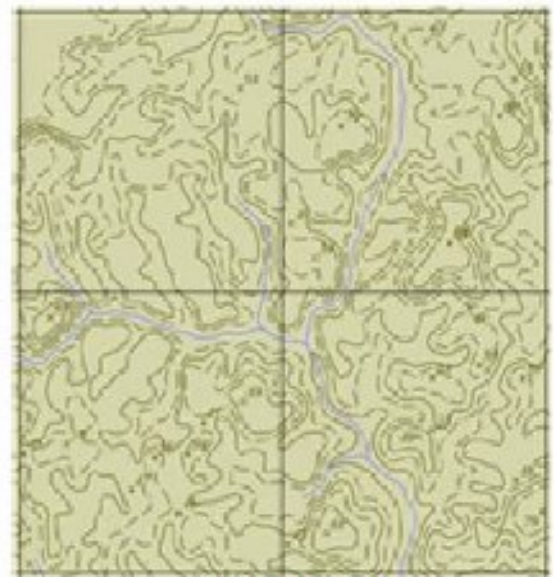

TRECHO III

Fonte: Adaptado de BDGEX (2021).

Figura 7 - Trechos dos produtos utilizados e as simulações geradas pelo Color Oracle para a deficiência Protanopia.

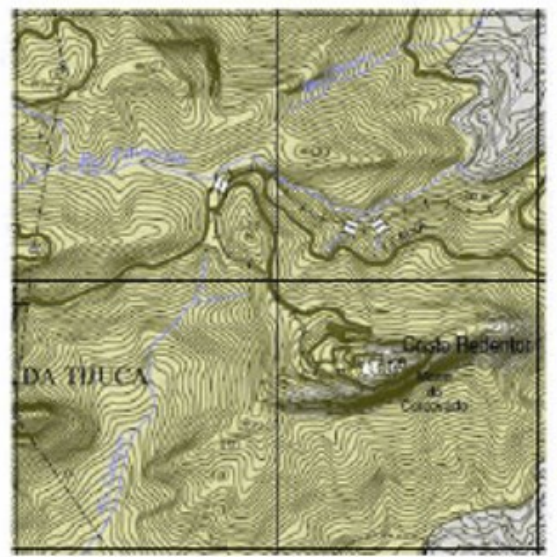

TRECHO I

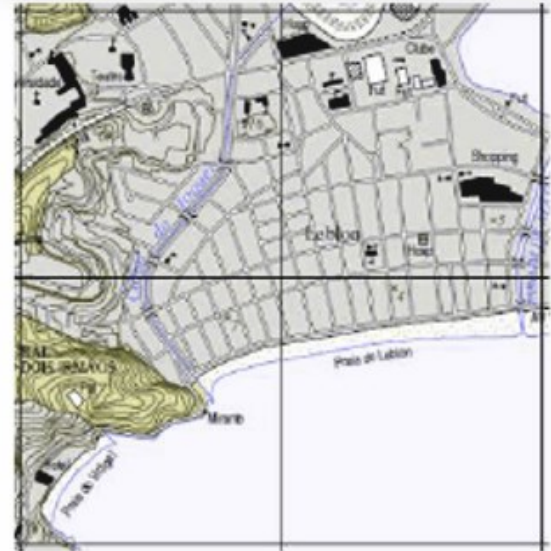

TRECHO II

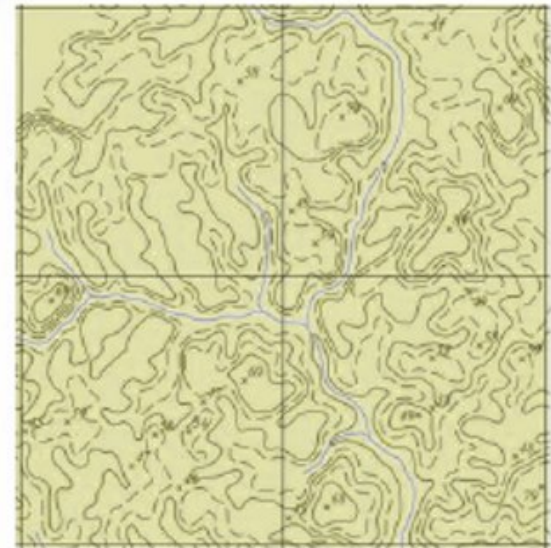

TRECHO III

Fonte: Adaptado de BDGEX (2021). 
Figura 8 - Trechos dos produtos utilizados e as simulações geradas pelo Color Oracle para a deficiência Tritanopia.

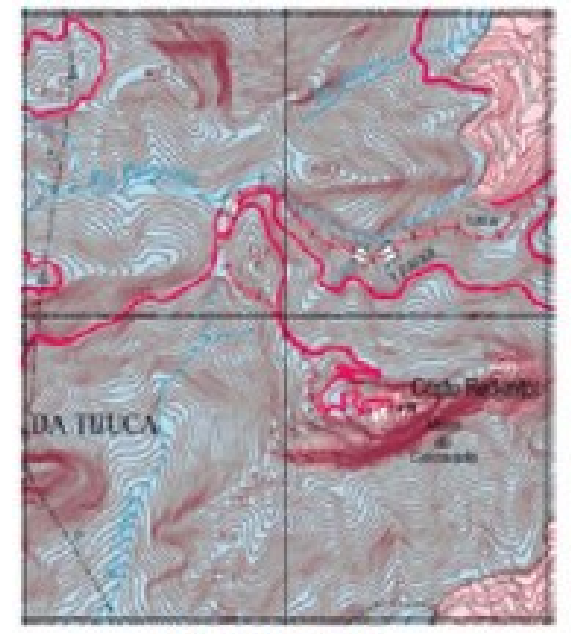

TRECHO I

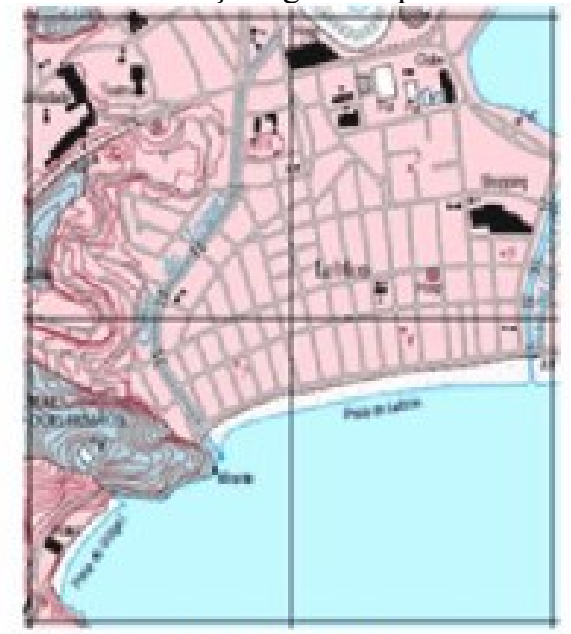

TRECHO II

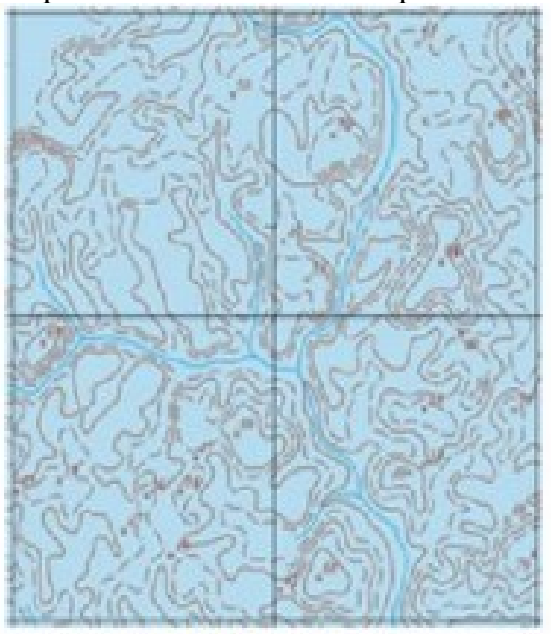

TRECHO III

Fonte: Adaptado de BDGEX (2021).

O questionário foi desenvolvido para ser respondido em meios digitais por voluntários daltônicos, sendo composto por três grupos de perguntas. O primeiro refere-se às questões gerais sobre as condições de visão do entrevistado, idade, sexo e familiaridade com os produtos que são objeto do estudo. O segundo é relacionado ao Teste de Ishihara, com indicativo de possível presença ou ausência de problemas na percepção de cores. Já o último grupo de perguntas é referente a questões específicas sobre representações gráficas das cartas topográficas SF-23-Z-B-IV4-SO e SB-21-V-B-II-2. Por envolver pesquisa com seres humanos, o projeto e seus anexos foram submetidos ao Comitê de Ética em Pesquisa (CEP) da UFV. Após a aprovação, procedeu-se a aplicação dos questionários por meio de formulários online.

Com os resultados do teste de Ishihara, os voluntários foram classificados entre usuários com deficiência na percepção de cores e usuários sem deficiência na visão de cores. Para a análise da influência desta condição na leitura e interpretação de produtos foi necessário levar em consideração os conhecimentos prévios de cada usuário na área da cartografia. Desta forma, foi criado um critério para mensurar a familiaridade dos voluntários com produtos cartográficos. O grau de familiaridade (GF) foi o valor adotado para realizar esta mensuração.

Esta medida constitui-se de um valor inteiro entre 0 e 100 gerado a partir das respostas aos três itens do formulário que dizem respeito aos conhecimentos em cartografia do participante. Como a familiaridade dos participantes com a cartografia e com os produtos a serem analisados é um fator que pode influenciar na interpretação dos produtos, foram elaborados 3 questionamentos sobre o assunto a fim de separar os usuários nos grupos com critérios objetivos. Para fins de classificação, foram atribuídos os seguintes pesos às questões:

A resposta ao primeiro item era um número inteiro entre 0 e 5 . Ao item foi dado o peso de $60 \%$ do total dos resultados, sendo esse multiplicado por 12 . Aos itens 02 e 03 foram dados os pesos de $15 \%$ e $25 \%$.

Pergunta 01: Em uma escala de 0 a 5, como você classificaria seus conhecimentos prévios em cartografia? (Zero significa que nunca teve contato e 5 que possui conhecimentos avançados).

Pergunta 02: Em seu cotidiano, estudos ou trabalho você costuma ter contatos com cartas topográficas?

Pergunta 03: Você tem familiaridade com os produtos cartográficos gerados pela Infraestrutura Nacional de Dados Espaciais (INDE)?

Desta forma, para realização das análises, os voluntários foram divididos em quatro grupos:

- Grupos CF e CN: constituídos pelos indivíduos com deficiência na percepção de cores e, respectivamente, mais familiarizados $(\mathrm{CF})$ e menos familiarizados $(\mathrm{CN})$ com os produtos em análise;

- Grupos SF e SN: constituídos pelos indivíduos sem deficiência na percepção de cores e, respectivamente, mais familiarizados (SF) e menos familiarizados (SN) com os produtos em análise. 
No trecho I foi avaliada a capacidade de identificação de uma feição linear. O objeto foi escolhido de modo que sua forma por si só não indicasse diretamente a sua classe. Foram realizadas também análises da visibilidade dos cursos d'água e de suas respectivas legendas, além do levantamento de eventuais melhorias no produto.

Para o trecho II, as questões tinham como objetivo aferir a capacidade de visualização e identificação de uma feição linear com a legenda. Além disso, avaliaram-se o contraste entre elementos e a capacidade de leitura da legenda de um curso d'água.

No trecho III também foi avaliado o contraste entre os rios e o restante contido no mapa. Além disso, foram coletadas sugestões para melhoria deste contraste. A hierarquia entre os objetos também foi avaliada com a seguinte pergunta: "Qual objeto você considera possuir maior destaque na imagem (Qual deles chama mais atenção à primeira vista)?".

Visando quantificar os resultados para uma análise mais geral, foi definido o Grau de Dificuldade (GD) que consiste de um número inteiro que varia de 0 a 100 . Quanto menor o grau de dificuldade, menores os problemas que o indivíduo enfrentou na leitura e interpretação dos produtos em análise. As variáveis envolvidas são o número de questões com erros $(\mathrm{E})$, as notas dadas às questões sobre a qualidade do contraste (C1 e C2), o número de questões onde foram apontadas necessidade ou possibilidade de melhorias (M) e a soma total pontos possíveis de se obter nas questões (T). As variáveis $\mathrm{C} 1$ e $\mathrm{C} 2$ receberam valor 0 ou 1 de acordo com o seguinte critério: Se a nota para o contraste dada pelo usuário é maior que três (possuindo valor máximo igual a 5), a variável correspondente recebe 1; caso contrário é atribuído o valor 0 . O GD foi calculado conforme a Eq. (1).

$$
G D=100 x \frac{E+C 1+C 2+M}{T}
$$

\section{RESULTADOS E ANÁLISES}

No total, foram recebidas respostas de 70 participantes. Sendo assim, o primeiro passo foi a realização dos cálculos do Grau de Familiaridade. Com isso, os indivíduos com e sem deficiência na visão de cores foram divididos em grupos de maior e menor familiaridade com os produtos analisados. O gráfico apresentado na Figura 9 mostra a distribuição numérica e percentual dos voluntários em cada um dos grupos.

Figura 9 - Distribuição dos participantes segundo cada grupo.

\section{NÚMERO ABSOLUTO; PERCENTUAL}

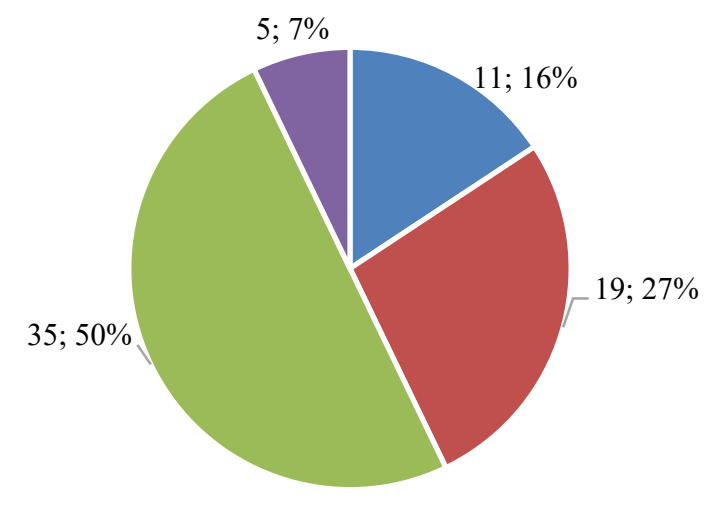

- Com Deficiência Mais Familiarizados (CF)

- Com Deficiência Menos Familiarizados (CN)

- Sem Deficiência Mais Familiarizados (SF)

- Sem Deficiência Menos Familiarizados (SN)

Fonte: Os autores (2021). 
Divididos os grupos, foi possível iniciar as análises detalhadas de cada trecho conforme as respostas dos formulários. Iniciando pelo trecho I, tem-se:

Os voluntários foram questionados sobre a classe correspondente ao objeto apontado pela seta 2 na Figura 10. O percentual de indivíduos que responderam corretamente em cada grupo encontra-se indicados na Tabela 1. Ao se comparar os resultados dos grupos de familiaridade equivalente, o percentual de acertos dos grupos de indivíduos com deficiência na visão de cores foi menor em ambos os casos. Entretanto, visto que o número de pessoas sem deficiência e familiarizado correspondem a $50 \%$ dos voluntários, a porcentagem também é considerada baixa também para esse público.

Figura 10 - Trecho I utilizado no questionário.

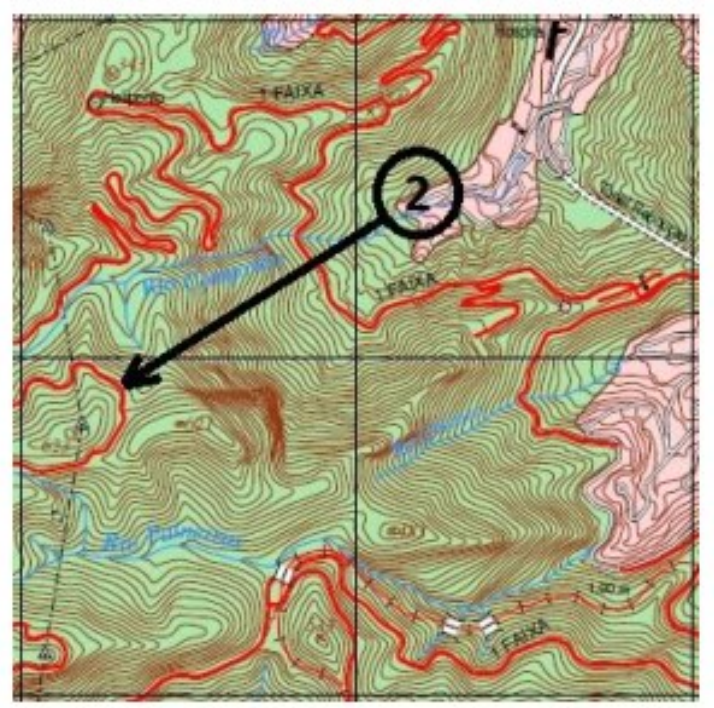

Fonte: Adaptado de BDGEX (2021).

Tabela 1 - Número de usuários que responderam corretamente à questão.

\begin{tabular}{cccc}
\hline $\mathbf{C F}$ & $\mathbf{C N}$ & $\mathbf{S F}$ & $\mathbf{S N}$ \\
\hline $2(18,2 \%)$ & $5(26,3 \%)$ & $10(28,6 \%)$ & $2(40 \%)$ \\
\hline
\end{tabular}

Fonte: Os autores (2021).

Já o gráfico da Figura 11 apresenta as sugestões de melhoria escolhidas pelos participantes para a seguinte pergunta: "Dentre as opções abaixo, assinale aquelas que te ajudariam a ter uma experiência melhor na leitura do mapa". Os usuários escolheram dentre as seguintes alternativas:

- $\quad 1^{\text {a }}$ - utilizar um azul mais forte para representar os rios;

- $\quad 2^{\mathrm{a}}$ - escrever o nome dos rios com uma fonte maior;

- $3^{\mathrm{a}}$ - alterar a cor do nome dos rios;

- $4^{\mathrm{a}}$ - utilizar linhas mais grossas para representar os rios e;

- $5^{\mathrm{a}}$ - alterações na cor do fundo. 
Figura 11 - Sugestões de melhoria apresentadas.

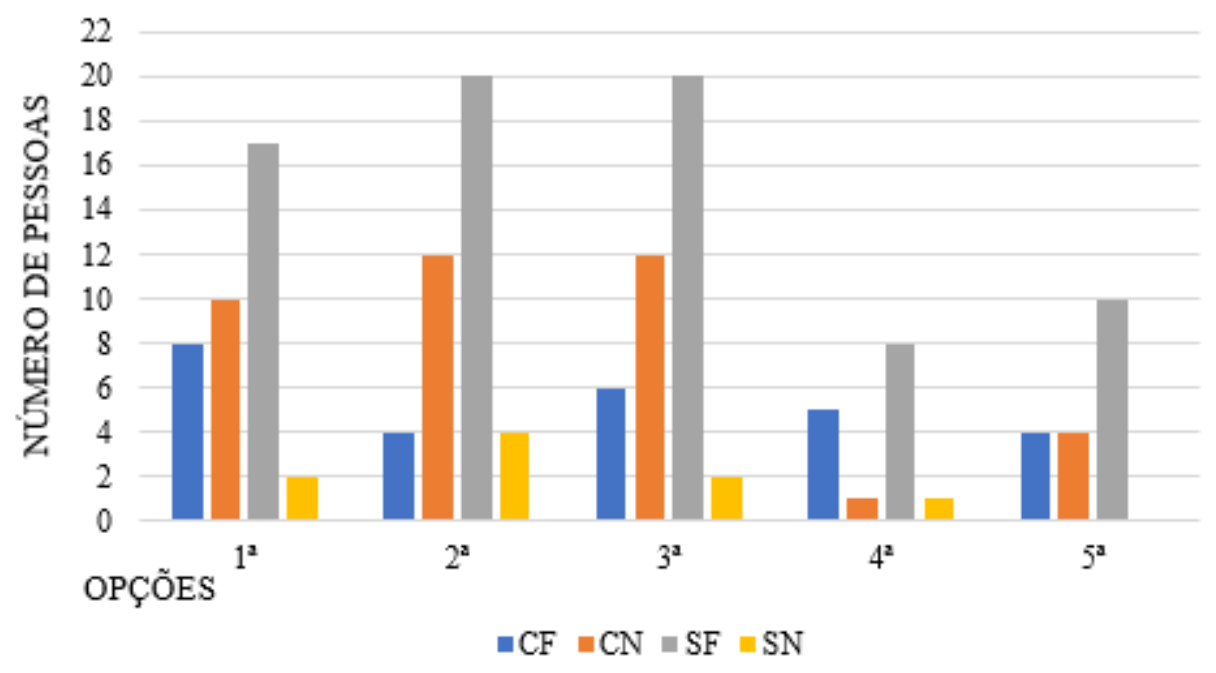

Fonte: Os autores (2021).

As três opções mais indicadas pelos integrantes do grupo CF foram a $1^{\mathrm{a}}$, a $3^{\mathrm{a}}$ e a $4^{\mathrm{a}}$. Nos demais grupos, as três opções mais indicadas foram a $1^{\mathrm{a}}$ a $2^{\mathrm{a}}$ e a $3^{\mathrm{a}}$. No grupo $\mathrm{CF}$, três pessoas sugeriram alteração do fundo para a cor branca, um dos usuários sugeriu alteração para a cor preta, dois usuários sugeriram alteração da cor do nome dos rios para preto, dois usuários propuseram a utilização de um contorno na fonte do nome dos rios de cor diferente da empregada no fundo do mapa. Um indivíduo do grupo $\mathrm{CN}$ também fez esta última sugestão; outro sugeriu "cores mais fortes" para o nome dos rios. Foi sugerida também a utilização de fontes e curvas de nível em preto. Ainda neste grupo, quatro pessoas sugeriram alteração do fundo para cor amarela, uma para roxo e outra sugeriu o fundo "com uma coloração mais clara" e as fontes "com cores mais intensas".

Em relação ao trecho II, todos os indivíduos, com exceção de 4 (21,1\% do total de integrantes do grupo) participantes do grupo $\mathrm{CN}$, afirmaram que conseguiram visualizar sem problemas o objeto indicado pela seta 1 na Figura 12. Quanto à identificação da feição em destaque, 3 (27,3\%) dos participantes do grupo CF não a identificou corretamente. Já entre os indivíduos do grupo CN, a incidência de erros foi de 63,2\% (12 participantes). Entre os não daltônicos, o grupo SF apresentou um percentual de erros de apenas $1(2,9 \%)$ enquanto no grupo SN, $8(40 \%)$ não identificou a feição. Dentre os indivíduos com algum tipo de deficiência na visão de cores, apenas $6(20 \%)$ declararam não ter dificuldades para realizar esta identificação. Entre aqueles que não possuem esta condição, este total foi de 31 (75,5\%). Novamente, a presença de deficiência na visão de cores parece ter influenciado na identificação das feições, tendo em vista os valores discrepantes nos erros de indivíduos que possuíam familiaridade com produtos cartográficos $(27,3 \%$ contra $2,9 \%)$ e sem essa familiaridade $(63,2 \%$ contra $40 \%)$.

Figura 12 - Trecho II utilizado no questionário.

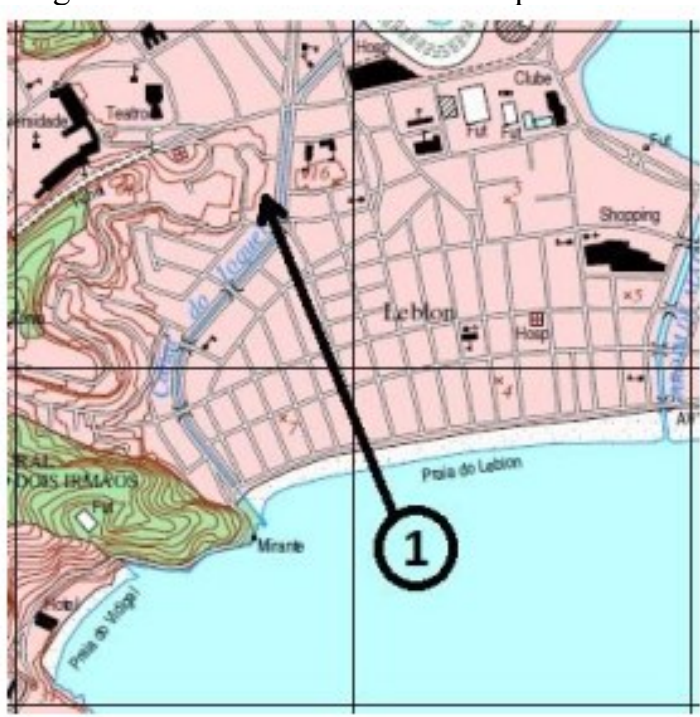

Fonte: Adaptado do BDGEX (2021). 
Os participantes ainda atribuíram notas para o contraste entre o fundo do mapa e os cursos d'água. A Figura 13 mostra o número de participantes que atribuíram cada nota em cada grupo. As notas médias foram 2,82 para o grupo $\mathrm{CF}, 2,68$ para o grupo $\mathrm{CN}, 3,57$ para o grupo $\mathrm{SF}$ e 3,80 para o grupo SN.

Figura 13 - Número de usuários a atribuir nota em para o contraste entre fundo de mapa e cursos d'água do trecho II.

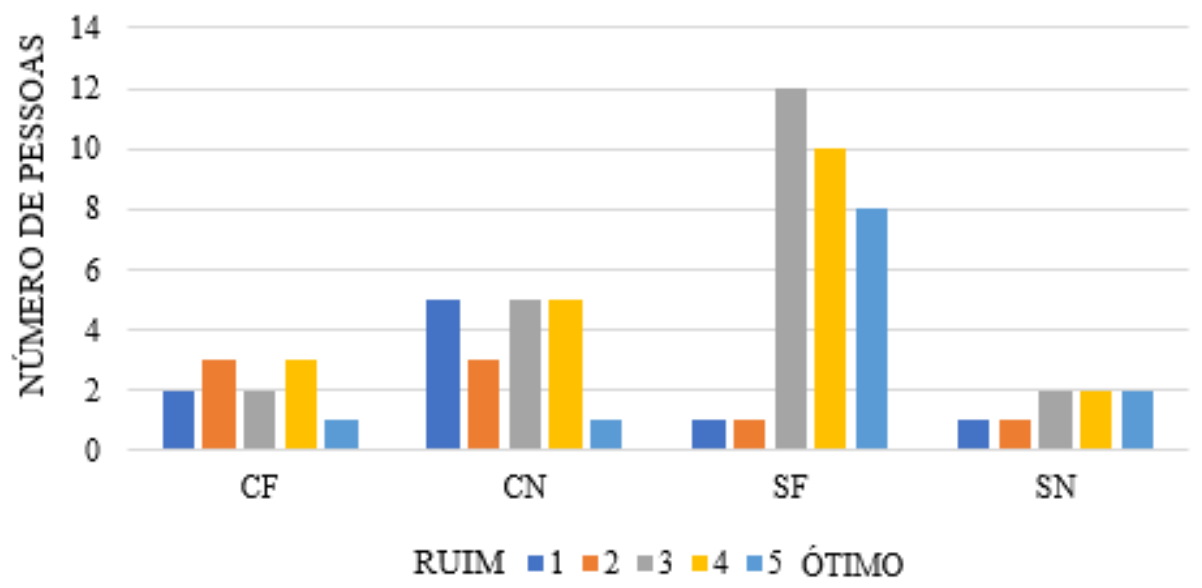

Fonte: Os autores (2021).

Já para o trecho III, utilizou-se a parte da carta apresentada na Figura 14.

Figura 14 - Trecho III utilizado no questionário.

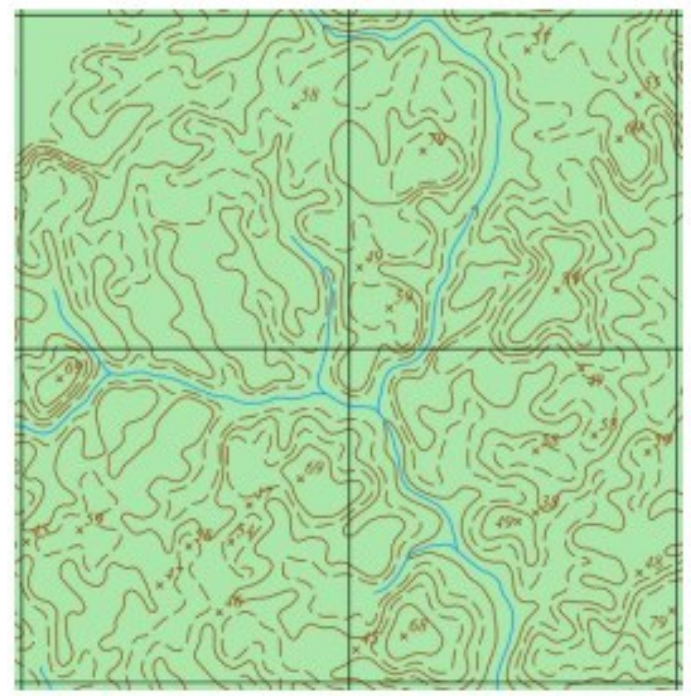

Fonte: Adaptado do BDGEX (2021).

Para este trecho, apenas um $(9,1 \%)$ indivíduo do grupo $\mathrm{CF}$ e um $(5,3 \%)$ do grupo $\mathrm{CN}$ afirmaram ter dificuldades na visualização dos cursos d'água. Os demais declararam que conseguiram distingui-los sem problemas dos demais elementos. Com a pergunta: "Qual objeto você considera possuir maior destaque na imagem?" procurou se avaliar a percepção de hierarquia entre os objetos pelos usuários. O gráfico da Figura 15 mostra a quantidade de pessoas em cada grupo que indicou cada elemento. 
Figura 15 - Número de usuários a atribuir nota em para o contraste entre fundo de mapa e cursos d'água do trecho III.

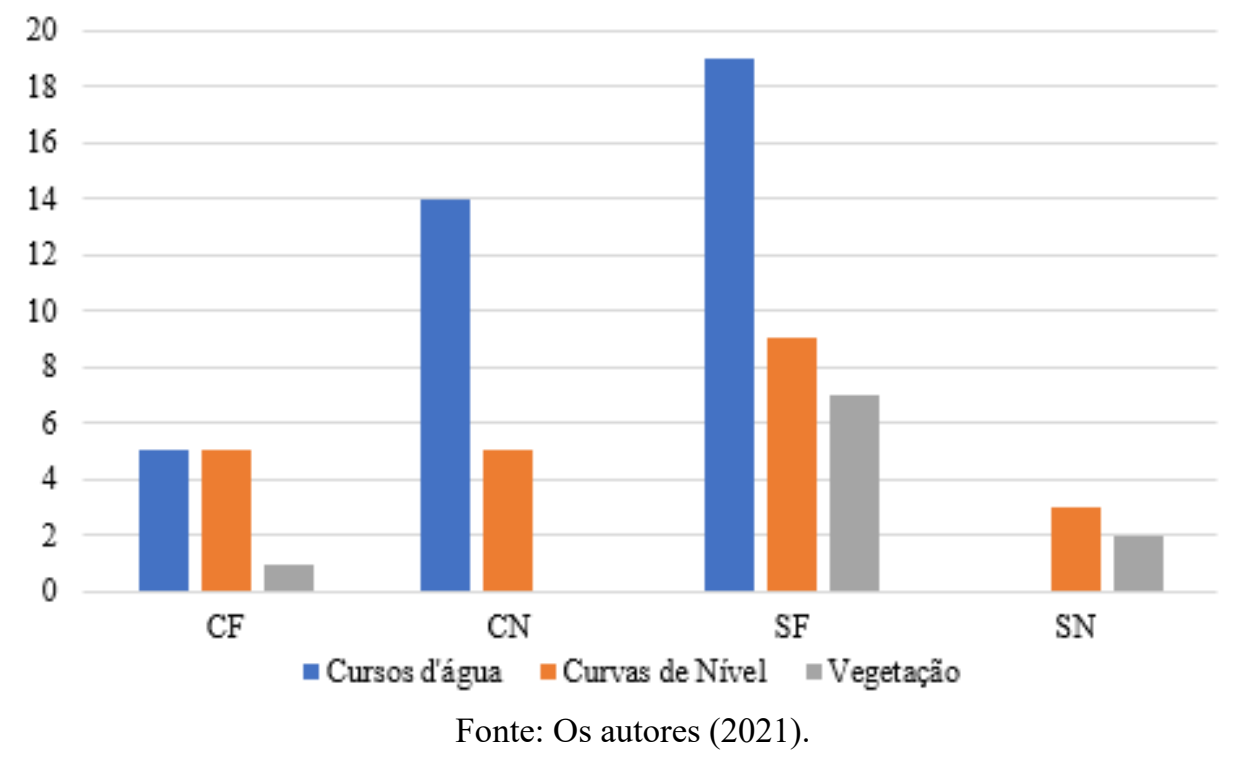

Os participantes atribuíram ainda notas para o contraste entre o fundo do mapa e os cursos d'água. A Figura 16 mostra o número de participantes que atribuíram cada nota em cada grupo. As notas médias foram 3,36 para o grupo $\mathrm{CF}, 3,63$ para o grupo $\mathrm{CN}, 4,06$ para o grupo SF e 4,20 para o grupo SN.

Figura 16 - Número de usuários a atribuir determinada nota em cada grupo.

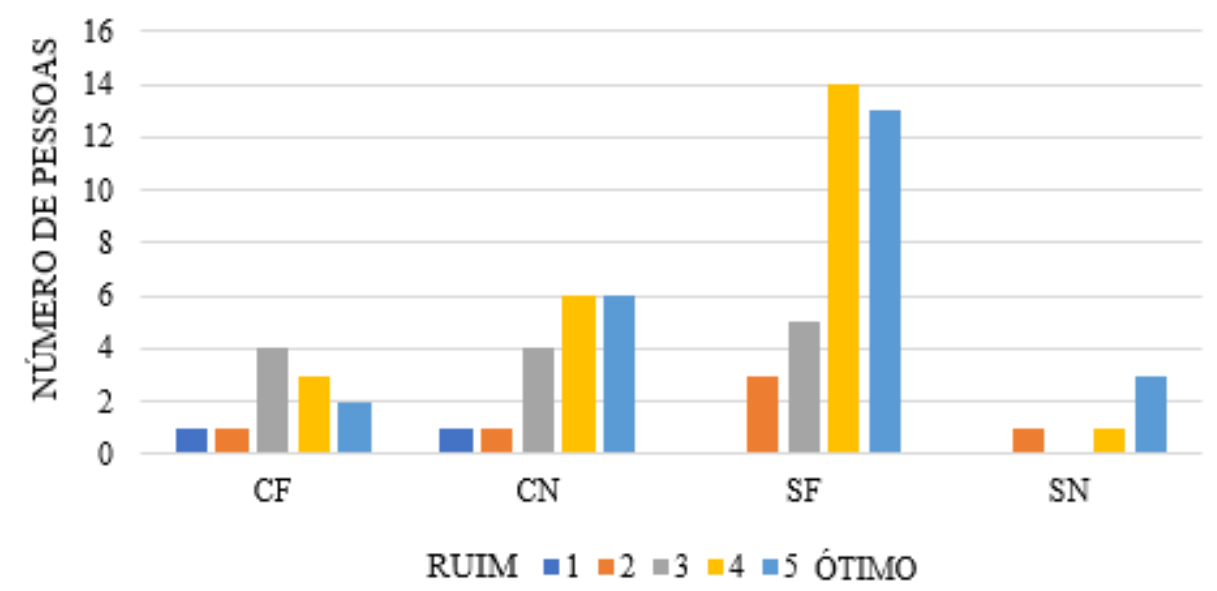

Fonte: Os autores (2021).

As sugestões de melhoria mais destacadas pelos entrevistados com deficiência na visão de cores dos dois grupos foram a utilização de linhas mais espessas ou de um tom de azul mais escuro na representação dos cursos d'água. Dois indivíduos do grupo CF ainda sugeriram utilização de tons mais claros para o fundo do mapa. Um voluntário apontou que uma ênfase maior no uso de "texturas e sobreposições" poderia facilitar a leitura do mapa.

No grupo CN dois usuários sugeriram a utilização de "cores mais vivas", enquanto outro sugeriu "cores mais neutras" para o fundo. Outro usuário propôs o uso de um verde que proporcionasse maior contraste com os elementos da carta. Alterações na espessura das feições lineares e emprego de cores mais leves para as curvas de nível também foram citados.

Em relação ao Grau de Dificuldade, o gráfico da Figura 17 apresenta o Grau de Dificuldade médio calculado para cada grupo. 
Figura 17 - Grau de Dificuldade médio calculado para cada grupo de voluntários.

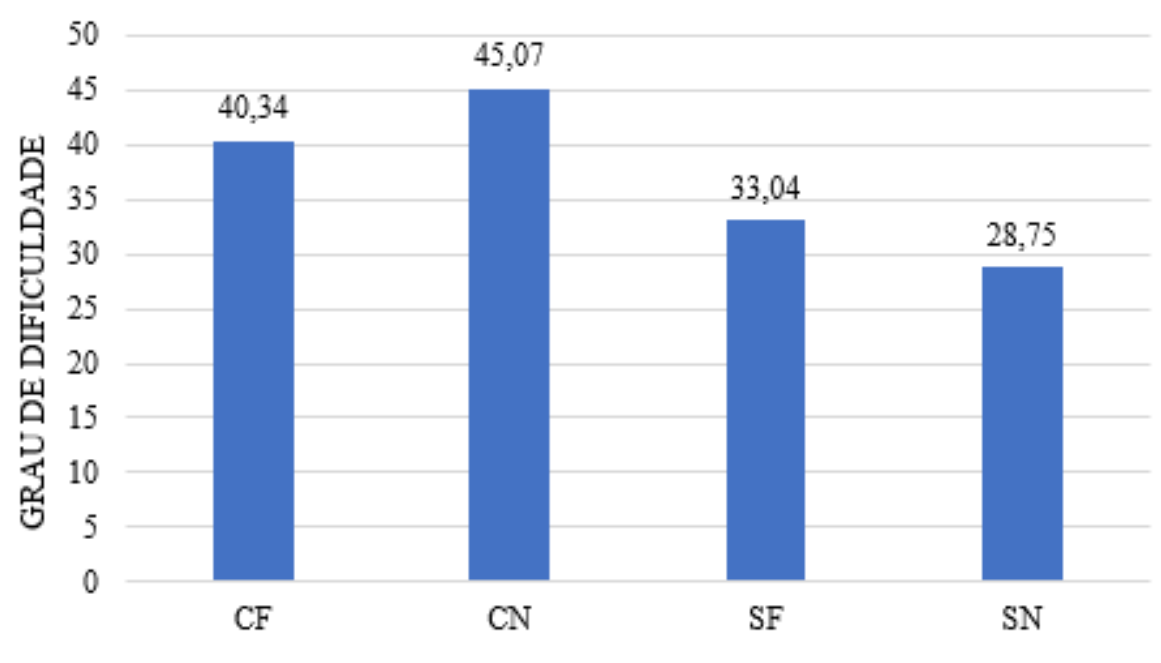

Fonte: Os autores (2021).

Nota-se, ao comparar o GD médio do grupo CF com o do grupo $\mathrm{CN}$, que a familiaridade auxiliou na leitura e compreensão dos indivíduos com deficiência na visão de cores, pois os indivíduos que possuíam tal familiaridade apresentaram menor GD. Já ao se comparar o grupo CF ao SF e o grupo CN ao SN, é possível notar que a deficiência na visão de cores provoca uma maior dificuldade na leitura e interpretação dos produtos cartográficos produzidos seguindo as diretrizes da ET-PCDG, independentemente da familiaridade que o usuário tenha com a cartografia, tendo em vista o aumento do GD. Ressalta-se que não era esperado o GD do grupo SN ser menor do que o grupo SF, entretanto tal fato pode ser justificado devido ao grupo SF ter considerado 35 pessoas, enquanto o grupo SN considerou apenas 5 .

\section{CONCLUSÃO}

Na maioria das análises foi possível notar que as experiências dos usuários com deficiência na visão de cores na leitura e interpretação dos produtos aparentemente foram prejudicadas por esta condição. Nas questões de identificação de feições com uso da legenda, especificamente para o trecho II, o percentual de erros entre grupos de usuários com esta limitação chegou a ser mais de 12 vezes maior que o do grupo de voluntários sem deficiência na visão de cores.

Quanto à percepção de hierarquia, os resultados não mostraram alterações significativas, exceto para o grupo sem deficiência e não familiarizados com produtos da INDE (SN). Em ambas as análises de contraste, as notas médias atribuídas pelos voluntários dos grupos compostos por pessoas com deficiência na visão de cores foram menores que a daqueles que não possuem a limitação. Esse resultado se mostrou válido independentemente de se levar em conta a familiaridade dos grupos aos produtos em análise.

Apenas participantes com deficiência na visão de cores mostraram dificuldade em visualizar os cursos d'água em um fundo verde. Por outro lado, no cenário com grande número de elementos concentrados do trecho II, houve dificuldade visualização e de leitura do nome dos cursos d'água pela maioria dos usuários de todos os grupos, de tal forma que nenhum deles conseguiu acertar os três nomes dos rios.

As sugestões de melhoria mais citadas pelos participantes dos grupos com deficiência e familiarizados com produtos da INDE (CF) e com deficiência e não familiarizados com produtos da INDE (CN) dizem respeito ao emprego de texturas, diferenciação da espessura de feições lineares, uso de cores mais contrastantes e de cores diferentes nas bordas dos textos contidos nos mapas.

De forma geral, constatou-se um maior Grau de Dificuldade médio dos grupos CF e sem deficiência com familiaridade com produtos da INDE (SF) quando comparado respectivamente ao dos grupos CN e SN. Era esperado que a familiaridade com os produtos cartográficos afetasse de forma positiva a qualidade da experiência dos usuários na leitura dos mapas. O que de fato ocorreu na comparação geral entre os grupos CF e CN, mas não foi constatado entre os grupos SF e SN. Neste caso, tanto a forma de elaboração do questionário quanto o número reduzido de usuários classificados no grupo $\mathrm{SN}$ podem ter interferido nos resultados. 
Durante a elaboração deste trabalho ficou evidente a dificuldade maior na leitura e interpretação dos produtos cartográficos para pessoas com deficiência na visão de cores. Seria interessante que para concluir a melhor forma de representação, fossem realizados demais testes em trabalhos futuros, visto que esse trabalho focou em analisar a adequabilidade das cartas aos usuários com deficiência na percepção de cores.

\section{Agradecimentos}

Os autores agradecem ao incentivo da Universidade Federal de Viçosa através principalmente do Comitê de Ética em Pesquisa (CEP), na realização deste trabalho por meio da aprovação dos questionários utilizados, além do apoio da Coordenação de Aperfeiçoamento de Pessoal de Nível Superior -Brasil (CAPES) - Código de Financiamento 001.

\section{Contribuição dos Autores}

Os autores Hélder do Carmo Dias e Jackson Viana Amarante realizaram as etapas de investigação, coletas de dados, metodologia, análise dos dados, redação e revisão do texto. Afonso de Paula dos Santos revisou todas as etapas, contribuiu com o texto e auxiliou o desenvolvimento da metodologia. Marconi Martins Cunha e Lígia da Silva Barbosa contribuíram com a pesquisa bibliográfica, redação e revisão do texto.

\section{Conflitos de Interesse}

Os autores declaram que não há nenhum conflito de interesse.

\section{Referências}

BEAR, M. F.; CONNORS, B. W.; PARADISO, M. A. Neurociências: Desvendando o sistema nervoso. $2^{\mathrm{a}}$ ed. Porto Alegre: Artmed, 2002.

BERTIN, J. Sémiologie Graphique: les Diagrammes, les Réseaux, les Cartes. Paris: Mouton, GauthierVillars, 452p, 1967.

BDGEX Banco de Dados Geográficos do Exército. Disponível em: < https://bdgex.eb.mil.br/mediador/>. Acesso em: 02 jan. 2021.

BIRCH, J. Worldwide prevalence of red-green color deficiency. Journal of the Optical Society of America A, 29(3), 313-320, 2012, DOI. 10.1364/josaa.29.000313.

BRASIL. Lei $\mathrm{n}^{\mathrm{o}}$ 10.098, de 19 de dezembro de 2000. Estabelece normas gerais e critérios básicos para a promoção da acessibilidade das pessoas portadoras de deficiência ou com mobilidade reduzida, e dá outras providências. Diário Oficial da União, Brasília, DF. Seção 1, p. 2. Disponível em:< http://www.planalto.gov.br/ccivil_03/leis/110098.htm>. Acesso em: 02 fev. 2021.

BRASIL. Decreto ${ }^{\circ}$ 6.666, de 27 de novembro de 2008. Institui a Infraestrutura Nacional de Dados Espaciais - INDE, e dá outras providências. Diário Oficial da União. Diário Oficial da União, Brasília, DF. Seção 1, p. 5. Disponível em: <http://www.planalto.gov.br/ccivil_03/_Ato20072010/2008/Decreto/D6666.htm>. Acesso em: em: 02 fev. 2021.

BRUNI, L. F.; CRUZ, A. A. V. Sentido cromático: tipos de defeitos e testes de avaliação clínica. Arquivos Brasileiros de Oftalmologia, 69, 5, 766-775, 2006. DOI. 10.1590/S0004-27492006000500028.

CUNHA, J. P. T. Influência dos Meios Oculares na Perceção do Teste de Visão das Cores de Ishihara. 89 f. Dissertação (Mestrado em Optometria Avançada) - Escola de Ciências, Universidade do Minho, Braga, 2019.

DAIN, S. J. Clinical colour vision tests. Clinical and Experimental Optometry, 87, (4-5), 276-293, 276293, 2004. DOI. 10.1111/j.1444-0938.2004.tb05057.x.

DANTAS, A. M. Doenças da Retina. Biblioteca Brasileira de Oftalmologia. $2^{\text {a }}$. ed. Editora Cultura Médica. 
Rio de Janeiro, 1996.

DENT, B. D.; TORGUSON, J. S.; HODLER, T. Cartography: Thematic Map Design. $6^{\circ}$ ed. Dubuque: Wm. C. Brown Publishers, 2009.

FAIRCHILD, M. D. Color appearance models. John Wiley \& Sons, 2013. DOI. 10.1002/9781118653128.

GOLDSTEIN, E. B. Sensation and perception. 8 ed. Wadsworth - USA. 2009.

IBGE. Projeções da População. Disponível em: https://www.ibge.gov.br/estatisticas/sociais/populacao/9109-projecao-da-populacao.html >. Acesso em: 19 jan. 2021.

JENNY, B.; KELSO, N. V. Color Design for the Color Vision Impaired. Cartographic Perspectives, 58, 6167, 2007.

KIM, Y. K.; KIM, K. W.; YANG, X. Real time traffic light recognition system for color vision deficiencies. In: 2007 International Conference on Mechatronics and Automation. IEEE, p. 76-81, 2007.

KRÖGER, J.; SCHIEWE, J.; WENINGER, B. Analysis and Improvement of the OpenStreetMap Street Color Scheme for Users with Color Vision Deficiencies. In: $\mathbf{2 6}^{\text {th }}$ International Cartographic Conference, 2013.

MACEACHREN, A. M. How maps work: Representation, Visualization and Design. London: The Guilford Press, 1995.

MAIA, A. F. D. V. M. Representação Gráfica de Mapas Para Daltônicos: Um Estudo de casos dos Mapas da Rede Integrada de Transporte de Curitiba. Dissertação (Mestrado em Design) - Programa de Pós Graduação em Design, Universidade Federal do Paraná, Curitiba, 2013. 21p.

MAIA, A. F.; SPINILLO, C. G. Como os daltônicos percebem as representações gráficas de mapas: um estudo de caso dos códigos de cores utilizados nos diagramas e estação-tubo do transporte público de Curitiba. Design e Tecnologia, 3, 5, 15-23, 2013. DOI. 10.23972/det2013iss05pp15-23.

MARTINELLI, M. Mapas da Geografia e Cartografia Temática. São Paulo: Contexto, 2007.

MOLLON, J. D.; POKORNY, J.; KNOBLAUCH. K. Normal and defective colour vision. New York: Oxford University Press, 2003.

NEIVA, M. Sistema de Identificação de Cor para Daltônicos: Código Monocromático. Dissertação de Mestrado. Universidade do Minho, Portugal, 2008.

NELSON, D. L.; COX, M. M. Princípios de bioquímica. 6a ed. Artmed Editora, 2014.

OLIVEIRA, R. F. Mapas De Guia De Rota Em Automóvel Para Motoristas Com Deficiência Na Visão De Cores. 118 f. Dissertação (Mestrado em Ciências Cartográficas) - Faculdade de Ciências e Tecnologia, Universidade Estadual Paulista, Presidente Prudente, 2015.

OLIVEIRA, R. F; RAMOS, A. P. M.; PUGLIESI, E. A.; DECANINI; M. M. S. Análise de representações cartográficas com base na percepção de cores dos daltônicos. In: SIMPÓSIO BRASILEIRO DE SENSORIAMENTO REMOTO, 2015, João Pessoa. Anais... 6258-6264.

PETERSON, G. N. GIS Cartography: a guide to effective map design. CRC Press, Nova Iorque, 2008.

POKORNY, J.; SMITH, V. C.; VERRIEST, G.; PINCKERS, A. J. L G. Congenital and Acquired Color Vision Defects. Grune and Stratton, New York, 1979.

SARDEGNA, J.; SHELLY, S.; RUTZEN, A. R.; STEIDL, S. M. The Encyclopedia of Blindness and Vision Impairment. 2 ed, New York: Facts on File, 2002.

SILVA, P. L.; SANTOS, A. P.; LISBOA FILHO, J. Proposal of an Academic Spatial Data Infrastructure for the Federal University of Viçosa. International Journal of Spatial Data Infrastructures Research, 88109. 2020. http://dx.doi.org/10.2902/1725-0463.2020.15.art4.

SILVEIRA, M. V.; BARTHEM, R. B. Ensino da visão cromática através de aparato com LED's coloridos. Revista Brasileira de Ensino de Física, 38, 3, 2016. DOI. 10.1590/1806-9126-RBEF-2016-0023.

URBANO, L. C. V. Discromatopsia: Métodos de Exame. Arquivos Brasileiros de Oftalmologia, 41, 5, 236$252,1978$. 


\section{Biografia do autor principal}

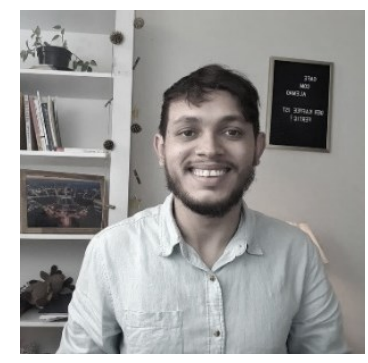

Helder do Carmo Dias nasceu em 1992 e é Engenheiro Agrimensor e Cartógrafo pela Universidade Federal de Viçosa com graduação sanduiche na Hochschule Karlsruhe. 